\title{
REQUIREMENTS FOR ESTABLISHING INNOVATIVE RURAL INSTITUTIONS TO PROMOTE THE FOOD SECURITY OF RICE GROWERS IN MAZANDARAN, IRAN
}

\author{
ZAMANi-Alaei, M. ${ }^{1}$ - FARAJOLlah-Hosseini, S. J. ${ }^{2 *}$ - Mirdamadi, S. M. ${ }^{1}$ - LASHGARARA, F. ${ }^{2}$ \\ ${ }^{I}$ Department of Agricultural Development, Science and Research Branch, Islamic Azad \\ University(IAU), Tehran, Iran \\ ${ }^{2}$ Department of Agricultural Extension and Education, Science and Research Branch, Islamic \\ Azad University(IAU), Tehran, Iran \\ *Corresponding author \\ e-mail: Jamalfhosseini@ srbiau.ac.ir \\ (Received $31^{\text {st }}$ Dec 2017; accepted $16^{\text {th }}$ Apr 2018)
}

\begin{abstract}
The issue of food security is considered an inseparable part of international development policies, so creating a nationally effective system to ensure food security, in addition to supporting the nutrition and health of the community, improves food industry status and increases production and income levels. To this end, the present study was carried out to identify the essential requirements for establishing innovative rural institutions to improve the food security of rice growers in Mazandaran, Iran. Economic, socio-cultural, infrastructure, policy-making, educational, and technical requirements were investigated, with each considered an observed variable with some items for each and to survey the impact of them on dimensions of food security and finally food security itself. The dependent variable was food security, measured by the five dimensions of availability, access, use, sustainability and safety. From a total of 113,141 rice growers in Mazandaran Province, Iran 216 were selected as the sample according to the Cochran method. Structural equation modelling and Amos 22 software were used in this study. The results showed that all six requirements mentioned above have an effect on food security, with technical requirements exhibiting the greatest effect, with a coefficient of 0.914. Suggestions are proposed for implementing these requirements.
\end{abstract}

Keywords: innovative organizations, rural institutions, food security, rice growers, small-scale farmers, requirements

\section{Introduction}

Food security is a great challenge, and due to food prices and global economic crises, the number of malnourished people has meteorically increased (Herbel et al., 2012). The Food and Agriculture Organization (FAO, 2010) has expressed that "Food security exists when all people at all times have physical and economic access to healthy, adequate and nutritious food to meet dietary requirements and food preferences for an active and healthy life." Food security is important because the goal of ensuring food security addresses all aspects of development. Food security is a complex concept with three basic pillars: 1) the availability of food, which means a sufficient amount of food based on a stable diet; 2 ) access to food, which means the ability to obtain adequate and nutritious food; and 3) the use of food, which means meeting food needs and cultural preferences (Asian Development Bank, 2013).

Finally, according to various researchers, food security can be divided into five elements: sustainability, availability, accessibility, utility, and safety. To conduct a comprehensive analysis and discussion, identifying the relationship among all five elements is necessary (Pereira et al., 2014). 
To reduce future food insecurity, the International Food Policy Research Institute (IFPRI) recommends a revision of the global food system focusing more on quality (nutrition) and safety and diversity than on expertise; a reduction in food and waste losses; and gender issues. Increasing sustainable products should focus on nutrition. To achieve this goal, approaches have been suggested that include investing in agricultural research and development to produce more nutritious food, leveraging more small-scale agricultural production for the value chain with a greater sensitivity to food quality (being nutritious), empowering women to link farming with nutrition, supporting policies and institutions for better nutrition and ensuring security in food systems (European Commission, 2015).

The latest estimates of the FAO show that a reduction in global hunger is continuing; from 2012 to 2014, approximately 805 million people in the world suffered from chronic malnutrition, a decrease of 100 million over the last decade of approximately 209 million people compared to 1990-1992. Since 1990, the prevalence of malnutrition in the world has fallen from $18.7 \%$ to $11.3 \%$, and in the developing world, it has dropped from $23.4 \%$ to $13.5 \%$. The FAO developed the Food Insecurity Experience Scale (FIES) to fill the global gap of food security monitoring, especially for assessing access levels at the individual and household levels. The FIES measures the severity of food insecurity, which is described as the number of people experiencing problems in obtaining food. The measurement of food insecurity through experience-centric scales is not an entirely new approach. These types of scales have been widely used to assess food insecurity in the United States since 1995. Similar tools such as the Household Food Insecurity Access Scale, Food and Nutrition Technical Assistance (FANTA) and the FAO Food Security Scale in the Caribbean and Latin America are currently being accepted at national, regional and project levels (FAO, IFAD and WFP, 2014).

In Iran, as in many countries, food security has been addressed through agricultural and rural development approaches, and there have been ongoing efforts to increase food availability in rural and urban communities (Hamidifar, 2012). According to Bakhshi et al. (2008), Iran's ranking in Southwest Asia based on indices of vulnerability and food security showed that Iran has high nutritional energy consumption, ranked sixth. In terms of the combined index of nutrition and food security, Iran is the twelfth-ranked country in Southwest Asia. In the economic access index, Iran is ranked fourteenth; in the agricultural macroeconomic index, fifth; in food availability index, fifteenth; in the cultural-health index, tenth; and in the total index of vulnerability, ninth. Moreover, Iran ranked first among the least vulnerable countries among the twenty countries in the region. Food security studies have identified food insecurity as a major problem in most societies with respect to the amount of food intake and nutritional, economic, social and cultural status (Rostami et al., 2014).

Rice is one of the cheapest and most effective foods available to eliminate acute malnutrition. Many studies show great potential for increasing rice production, especially in Asia. Food security in Asia has traditionally been defined as maintaining basic prices for rice in the main rural markets in the country, which provide the main food supply to more than $50 \%$ of the population. Thus, reaching self-sufficiency in terms of rice production is an effective method to promote food security at the national level. Sustainable production of rice in South Asia is the main source of food security in this region. Rice paddies have full potential for self-sufficiency in rice production, as is currently occurring in India and Pakistan. Since poverty is one of the factors directly affecting food insecurity, through employment in agricultural activities and projects 
currently underway in many countries in this area, people can escape extreme poverty. A survey conducted in South Asia shows that the easiest way to promote national food security is obtaining self-sufficiency in rice production (Bishwajit et al., 2013).

A study by John and Fielding (2014) in South Asia indicates that the most important limitation in rice production in this region is the socio-economic constraint of production, which was examined according to seven factors:

1. Difficult access to water for irrigation

2. Lack of quality grain

3. High cost of irrigation

4. Expensive nitrogen fertilizer of limited supply

5. Insufficient farmer knowledge

6. Lack of access to agricultural information

7. High prices of input

Given the above-mentioned issues, one can categorize the major issues and problems that have arisen due to the lack of attention to rural innovative institutions in achieving food security as follows:

1. Failure to achieve food security due to problems in the five aspects of availability, accessibility, utility, sustainability and safety (Herbel et al., 2012)

2. Failure to achieve food security due to the lack of access of small farmers to natural resources, productive assets, markets, and knowledge and information (Herbel et al., 2012)

3. Failure to achieve food security due to inappropriate management models in rural areas (Moradi and Popzan, 2014)

Among the most important benefits and achievements of this research is help in creating effective production organizations to improve food security. Overall, productive and sustainable production organizations and institutional arrangements with market agents and policymakers are also dependent on the three types of relationships developed by small-scale producers (Herbel et al., 2012):

1. Connection or linkage or intergroup relationships among small-scale producers within organizations

2. Establishing communication or inter-group relationships between small producer organizations to create reference organizations

3. Establishing communication or inter-group relationships between small producer organizations and market agents and policymakers

The main goal of this study is to finding the set of requirements that important for establishing rural innovative institutions to improve food security from rice grower's perspective in Mazandaran Province, Iran. In this regard, the following objectives were extracted:

- Recognizing the economic requirements to establishing rural innovative institutions for improving food security of rice growers in Mazandaran Province

- Recognizing the socio-cultural requirements to establishing rural innovative institutions for improving food security of rice growers in Mazandaran Province 
- Recognizing the infrastructural requirements to establishing rural innovative institutions for improving food security of rice growers in Mazandaran Province

- Recognizing the policy-making requirements to establishing rural innovative institutions for improving food security of rice growers in Mazandaran Province

- Recognizing the educational requirements to establishing rural innovative institutions for improving food security of rice growers in Mazandaran Province

- Recognizing the technical requirements to establishing rural innovative institutions for improving food security of rice growers in Mazandaran Province

\section{Theoretical framework}

Governments and international organizations are seeking effective institutional frameworks for managing and helping rural and agricultural development to address the challenges of increasing farmers' integration in local and regional markets and value chains, increasing public-private investment in agriculture, increasing concern regarding food security in the world, rural poverty, regional disparities, flexibility, and climate adaptability in land use. The overall challenge is to strengthen rural development processes in government to ensure positive effects and new opportunities for microfarmers, rural communities, local economies and communities and nations as a whole. The expected outcomes are to reduce vulnerability and increase social capacity, flexibility and sustainability in agricultural systems on a larger scale than exists today. New institutional arrangements and partnerships create a link between the private and public sectors needed to strengthen the governance of natural resources and land; improve information, consultation, and technical development; and support the families of farmers, communities, and rural areas to achieve sustainability (Natural Resources Institute, 2016).

Allameh (2012) described the following factors affecting food security:

- Political, social and economic stability

- Type of resources available to community producers

- Conservation and sustainable use of sustainable resources

- Different consumption cultures

- Level of income and financial ability of households

- Demographic indicators

- Price policies

- Rural and agricultural development

Allameh showed the aspects and components of food and nutrition security as presented in Figure 1.

Keshavarz and Karami (2014) investigated the causes and factors affecting food insecurity and provided recommendations for policymaking in the field of extension to improve the food security of rural households. The authors used the Sen (1981) perspective and the study by him as shown in Figure 2 to explain the framework for their research. 


\section{Production and Marketing (supply and distribution)}

in quality and quantity dimensions

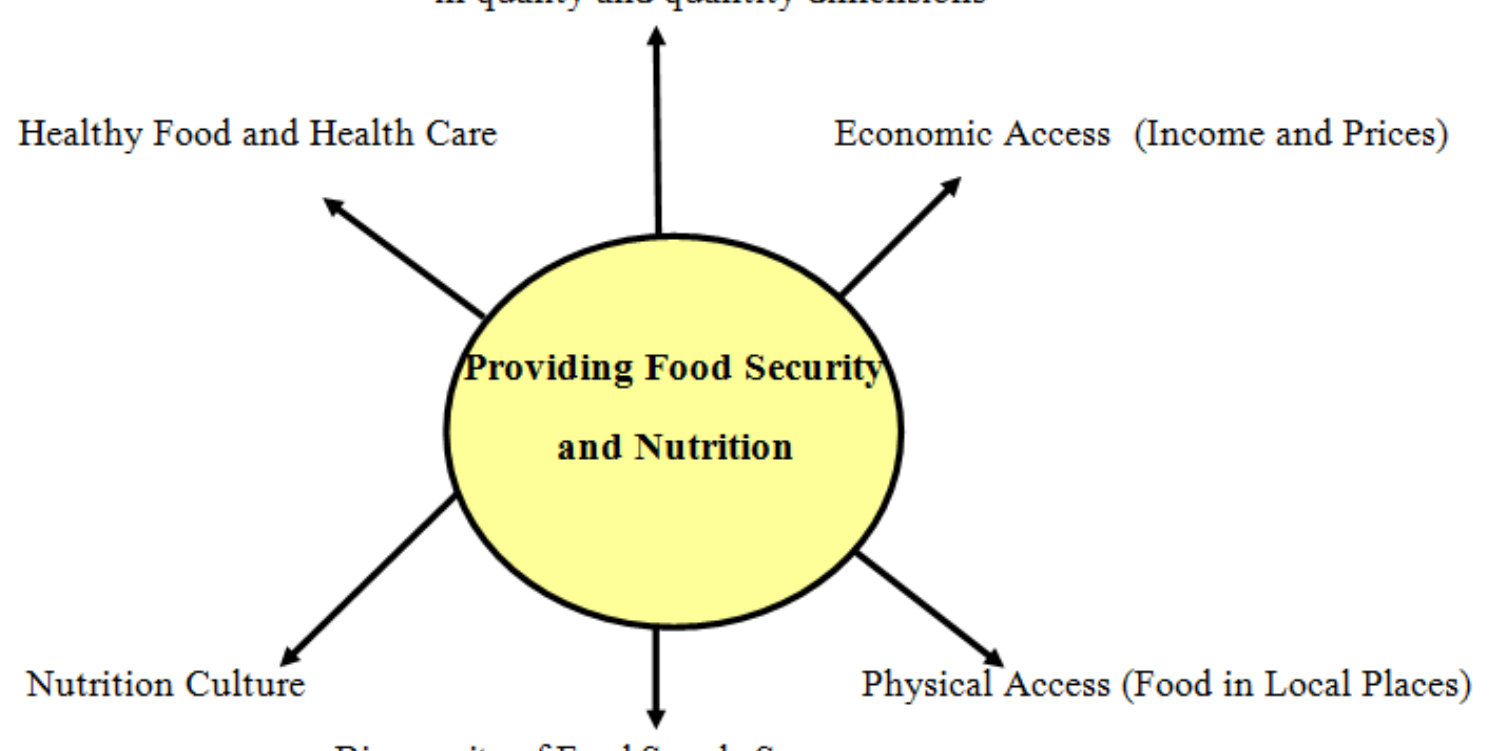

Biosecurity of Food Supply Sources

Figure 1. Main components of food and nutrition security. (Source: Allameh, 2012)

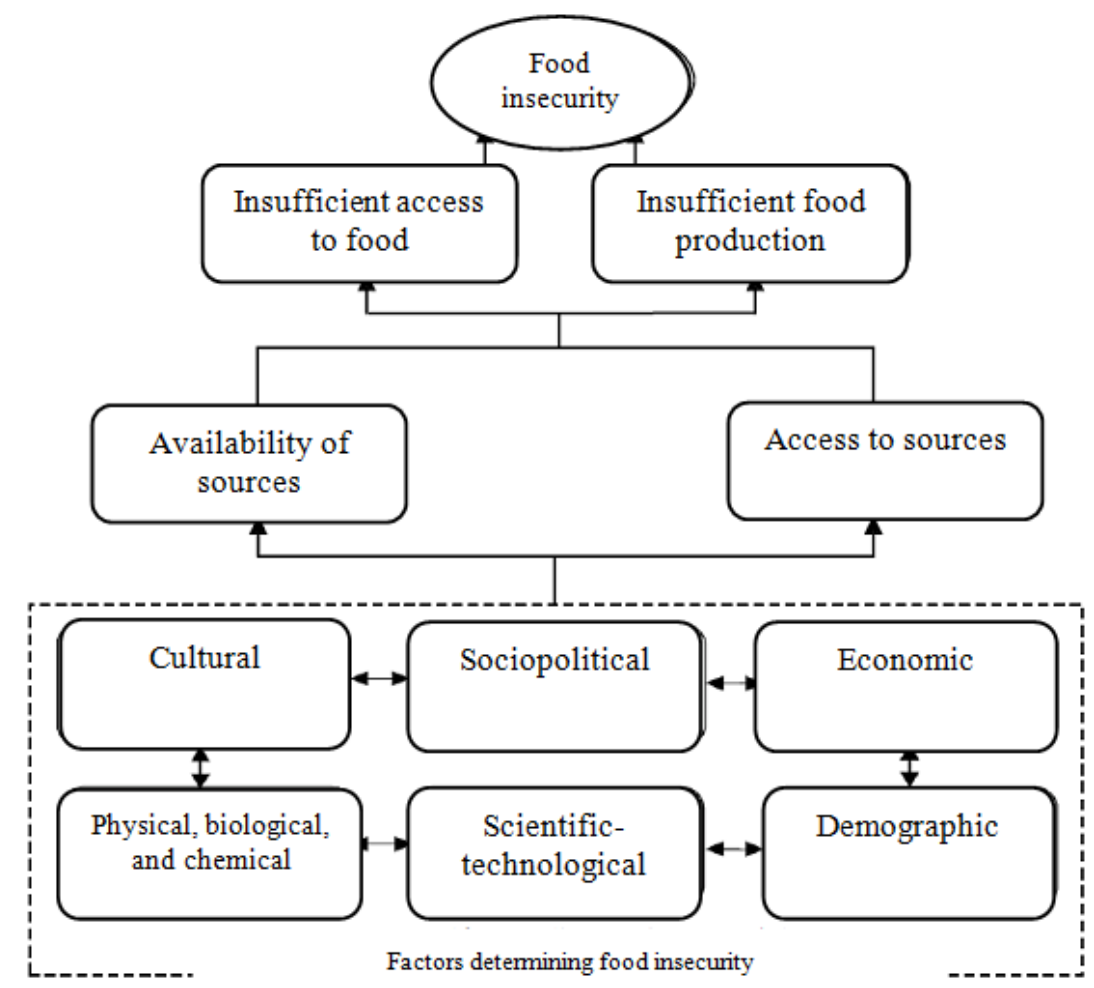

Figure 2. The conceptual framework of the food insecurity process of rural households

Based on the local of our research, Table 1 shows the GPS coordinates for Mazandaran Province (Survey Locality). 
Table 1. The GPS coordinates for Mazandaran Province, Iran

\begin{tabular}{c|c}
\hline Specifications & Coordinates \\
\hline Latitude & $37^{\circ} 7^{\prime} 18.04^{\prime \prime} \mathrm{N}$ \\
Longitude & $49^{\circ} 56^{\prime} 30.20 " \mathrm{E}$ \\
\hline
\end{tabular}

Figure 3 shows the map of Mazandaran Province's cities and roads include 22 cities and suburban that represent the selected statistical population in this research.

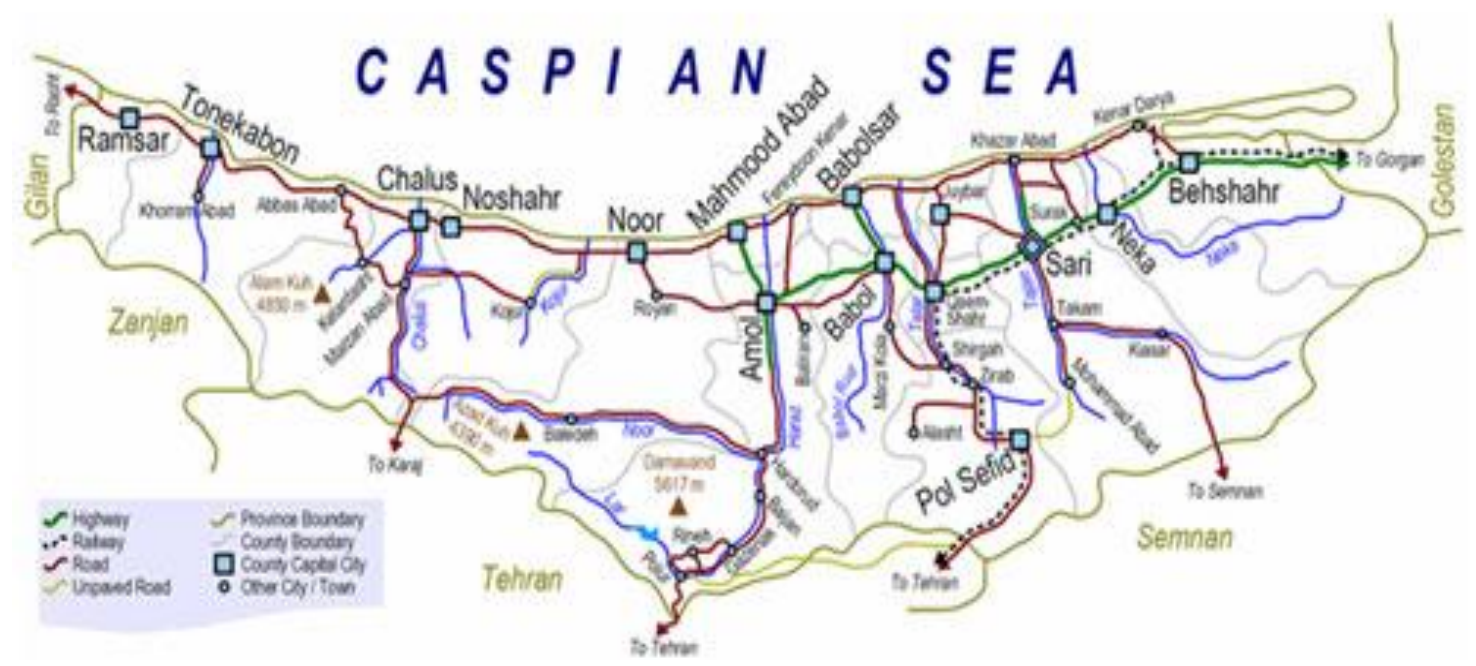

Figure 3. The map of Mazandaran Province and the cities

\section{Materials and methods}

The above-described principles and techniques were used in this study with the aim of solving executive problems and applying practical knowledge in Mazandaran province of Iran. The research process was both qualitative and quantitative and crosssectional in terms of the timeline. The research approach was quasi-experimental, and the researcher had some control over the variables. The study involved a survey considering data collection. The population consisted of 113,141 rice growers in Mazandaran and used a stratified random sampling method with proportional allocation. The original sample volume was determined using the Cochran formula (Eq. 1) for 216 people (Cronbach, 1951).

$$
n=\frac{N t^{2} s^{2}}{N d^{2}+t^{2} s^{2}}
$$

The tool used in this study for data collection was a questionnaire. The questionnaire consisted of eight sections:

- Section 1: Economic requirements (11 items)

- Section 2: Social-cultural requirements (10 items)

- Section 3: Infrastructure requirements (6 items)

- Section 4: Policymaking requirements (9 items) 
- Section 5: Educational requirements (7 items)

- Section 6: Technical requirements (6 items)

- Section 7: Personal treatments (15 items)

- Section 8: Food security dimensions (Availability (7 items), Accessibility (7 items), Utility (5 items), Sustainability (5 items), Safety (4 items))

To evaluate the content validity of the questionnaire, portions were provided to professors of agricultural promotion and development as well as to experts and specialists in the field of rice and members of the rice community. Cronbach's alpha method was used to calculate reliability. A pre-test was used, and 30 questionnaires were distributed among the rice growers to calculate Cronbach's alpha. Structural equation modelling using a classical approach was used, and SPSS 16 and Amos 22 software were used for analysis.

\section{Results}

\section{Describing the data}

For a better understanding of the nature of the population studied in the research and to become more familiar with the research variables, it is necessary to describe these data before the analysis of statistical data (Table 2).

Table 2. Demographic characteristics of the subjects $(n=216)$

\begin{tabular}{c|c|c|c|c|c|c}
\hline Items & Mean & Median & Mode & Min & Max & SE \\
\hline Age (year) & 51.68 & 50 & $40-50$ & 25 & 90 & 0.85 \\
\hline Gender & - & - & Male & & & \\
\hline Level of education & - & - & Diploma & & & \\
\hline Family members & 4 persons & & - & & & \\
\hline Land size (m²) & 7752 & 7000 & 8000 & 2000 & 50000 & 4.72 \\
\hline $\begin{array}{c}\text { Amount of yearly } \\
\text { rice production } \\
\text { (ton/year) }\end{array}$ & 3.35 & 3 & 2.4 & 0.50 & 25 & 0.23 \\
\hline $\begin{array}{c}\text { Experience in } \\
\text { agriculture }\end{array}$ & 27.27 years & 25 years & 30 years & 2 & 70 & 1.19 \\
\hline Ownership & - & - & Personal & & & \\
\hline $\begin{array}{c}\text { Familiar with Rice } \\
\text { Institution }\end{array}$ & - & - & No & & & \\
\hline $\begin{array}{c}\text { Membership in } \\
\text { Mazandaran's Rice } \\
\text { Institution }\end{array}$ & - & - & No & & & \\
\hline
\end{tabular}

Table 2 shows that the average age of respondents was over 51 and that most of them were males with a high school diploma. Moreover, the average number of people in households was 4, their average agricultural land area was less than 1 hectare, and they produced more than 3 tons of rice per year. A significant percentage of respondents were not only not members of their province's rice association but were not familiar with the association. 


\section{Inferential statistics}

To determine the estimation method for unknowns in the equation of structural equations, the contribution of each unknown to the parameter volume is first calculated. Given the sample size $(n=216)$ and the number of unknown parameters of the model $(\mathrm{NPar}=119)$, the contribution of each unknown parameter was calculated to be 1.81 (Eq. 2).

$$
\frac{n}{N P a r}=1.81
$$

However, given that all research questions had a 5-point Likert scale, the normal assumption of multiple-variable observations was not confirmed. There are two approaches for solving this problem: 1) using the Bayesian approach or 2) using the latent variable assignment approach to each question that has a Likert scale. In this research, we chose the second approach for the following reasons.

The measures to check goodness of fit using the Bayesian approach are mostly graphical, while in the classical approach, all criteria are quantitative and easy to compute and compare.

To use the Bayesian approach, it is better to have the statistical information of an expert population available to provide a useful analysis. If this is not the case, there are no significant differences between the Bayesian and classical approaches (Lee, 2007).

After assigning a latent variable with a normal distribution to items with Likert scales, using the AMOS22-embedded equation approach with ten times the original sample size, we generated 2160 random numbers from the normal multivariate distribution. The generated data with multivariate normal distribution were the basis of our calculation. As the share of each unknown parameter of 2160 generated randomized samples was 10.8 and there was a multivariate normal assumption, using the maximum likelihood method in the classical approach, the unknown parameters were estimated.

After charting using AMOS22 software, the software outputs are presented in tables as well as a graph of the structural equation model as shown in Figure 4.

We present some of the goodness-of-fit criteria of the model in Table 3.

Table 3. Some of the goodness-of-fit criteria of the model

\begin{tabular}{c|c|c|c|c|c|c}
\hline Model & $\mathbf{X}^{\mathbf{2}}$ Value & $\mathbf{d f}$ & $\mathbf{p}$-value & $\mathbf{X}^{\mathbf{2}} / \mathbf{d f}$ & $\mathbf{R M S E A}$ & $\mathbf{P r}$ (RMSEA $\leq \mathbf{0 . 0 5})$ \\
\hline Fitted model & 2974.055 & 2914 & 0.214 & 1.020 & $0 / 019$ & 0.999 \\
Saturated model & 0.000 & 0 & & & Uncountable & Uncountable \\
Dependence model & 4592.630 & 2926 & 0.000 & 1.569 & 0.103 & 0.000 \\
\hline
\end{tabular}

Given the goodness-of-fit criteria presented in Table 3, the p-value in the fitted model is 0.214 , which is greater than 0.05. Thus, it is at an acceptable level. The RMSEA value is 0.019 , which is less than 0.05 , and the chi square over the degree of freedom $\left(1<\mathrm{x}^{2} / \mathrm{df}<3\right)$ is calculated as 1.020 , both of which are acceptable. Therefore, the fitted model is a suitable and dependable model in terms of all criteria for goodness of fit. 


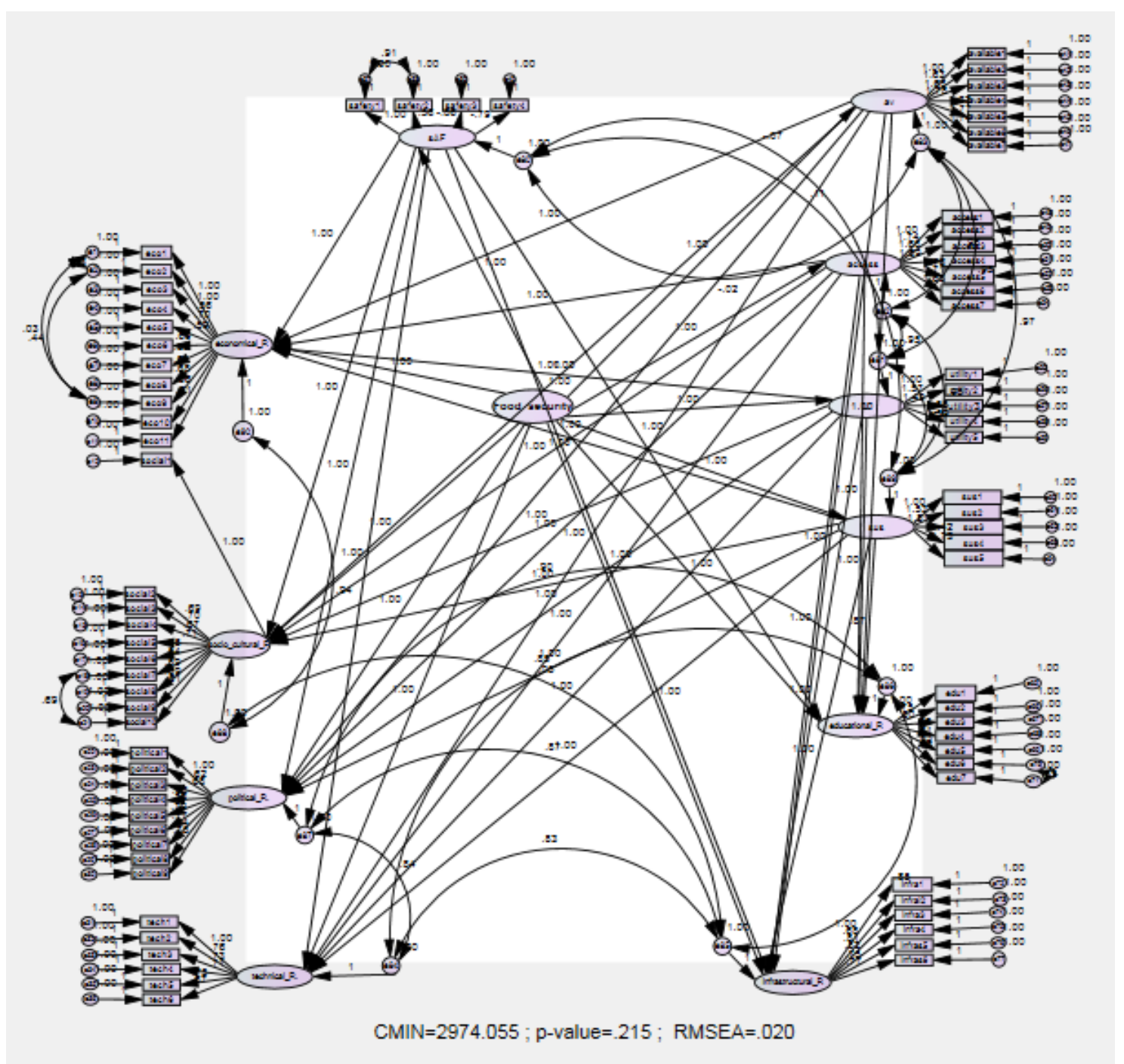

Figure 4. Model-fitted data model diagram

To determine the effect of each independent variable on the other dependent variables, we calculated the total effect (standardized) of all the paths (Table 4).

Table 4. Total effect level (standardized) of the research requirements on food security dimensions

\begin{tabular}{c|c|c|c|c|c|c}
\hline \multirow{2}{*}{ Independent variables } & \multicolumn{7}{|c}{ Dependent variable (dimensions) } \\
\cline { 2 - 7 } & Sustainability & Utility & Safety & Accessibility & Availability & Food security \\
\hline Technical requirements & 0.416 & 1.115 & 1.560 & 2.344 & 0.242 & 0.919 \\
Educational requirements & 0.080 & 0.137 & 0.699 & 1.196 & 0.312 & 0.914 \\
Social-cultural requirements & 0.165 & 0.376 & 1.068 & 1.456 & 0.630 & 0.862 \\
Infrastructure requirements & 0.292 & 0.630 & 1.035 & 1.789 & 0.701 & 0.844 \\
Policymaking requirements & 0.025 & 0.892 & 1.013 & 1.999 & 0.304 & 0.771 \\
Economic requirements & 0.181 & 0.765 & 1.339 & 2.113 & 0.923 & 0.757 \\
\hline
\end{tabular}


According to Table 4, the technical requirements had the greatest impact on food security, with a coefficient of 0.919 , followed by educational requirements with a path coefficient of 0.914 , socio-cultural requirements with a path coefficient 0.862 , infrastructure requirements with a coefficient of 0.844 , policymaking requirements with a path coefficient of 0.771 and, finally, economic requirements with a path coefficient of 0.775 . Moreover, by examining the effect of each of the requirements on the five aspects of food security, one can see that the technical, educational, socio-cultural, infrastructure, policymaking and economic requirements with path coefficients of $2.344,1.196,1.465,1.789,1.999$ and 2.113 , respectively, had the greatest impact on access to food security.

Table 5 summarizes the impact of each of the five dimensions of availability, access, use, sustainability and safety on food security.

Table 5. Total effect (standardized) of each dimension of food security on the dependent variable (food security)

\begin{tabular}{c|c}
\hline Independent variables (observed variables) & Dependent variable (food security) \\
\hline Availability & 0.672 \\
Accessibility & 0.642 \\
Sustainability & 0.632 \\
Utility & 0.629 \\
Safety & 0.521 \\
\hline
\end{tabular}

Table 5 shows the impact of each of the five aspects of food security on the dependent variable (food security), which, according to the results presented, shows that the dimension of availability is the most effective, with a coefficient of 0.672 , followed by access, sustainability, use and safety. The effect of each of the observed (independent) variables on food security (dependent variable) is presented in Table 6.

Table 6. The total effect of standardized variables on the dependent variable (food security)

\begin{tabular}{l|c}
\hline \multicolumn{1}{c|}{ Independent variables (observed variables) } & $\begin{array}{c}\text { Dependent variable } \\
\text { (food security) }\end{array}$ \\
\hline \multicolumn{1}{c|}{ Educational Requirements } & 0.808 \\
\hline - Launching publications and journals on rice crop operations & 0.811 \\
- Conducting workshops on rice crop operations & 0.810 \\
- Increasing human capital through training an expert force & 0.809 \\
- Using the FFS method and holding a rice farm day & 0.810 \\
- Organizing various local classes, such as development classes, etc. & 0.808 \\
- Strengthening the proper use of indigenous and local knowledge & 0.814 \\
- Strengthening access to knowledge and information & \\
\hline \multicolumn{2}{c}{ Technical Requirements } \\
- Using new technologies in agriculture, such as nanotechnology, nuclear & 0.812 \\
- technology, etc. & 0.807 \\
- Using proper technology in planting, preservation and harvesting & 0.806 \\
\hline
\end{tabular}


- Making multifunctional use of rice cultivation such as rice cultivation with breeding of ducks, fish, etc.

- Using hybrid seeds and modified varieties

- Using machines in transplantation

Infrastructure Requirements

- Creating industries and conversion and complementary enterprises in villages

- Improving access to information and communication technology (ICT)

- Improving the access of farmers to the proper equipment for the preparation and renovation of arable land

- Improving access of skilled rice growers to a proper transportation system

- Improving access of farmers to suitable arable lands for cultivation

- Strengthening the access of rice growers to water resources and optimal management

Policy-making Requirements

- Ensuring that the voices of small-scale producers are heard by the authorities to participate in the policymaking and decision-making process

- Promoting local governance and decentralization in rural management programs

- Integrating land under rice growth

- Adopting appropriate rules to reduce conflicts on land

- Creating a targeted, coordinated and coherent planning system in villages

0.801

- Improving product pricing policies

0.808

0.808

- Improving lending policies for subsidizing loans to rice growers

0.808

- Improving supportive policies for saving and securing energy

0.806

- Improving the import and export policies of rice crops

Sustainability (Food security)

- Managing and conserving resources, especially water resources, for sustainable livelihoods

- Managing risk in rice production (use of inputs, weather conditions, etc.)

- Confronting the structural causes of food insecurity

- Monitoring food security and finding effective factors in the vulnerability of rice growers

- Creating diversity in agriculture and employment

$$
\text { Utility (Food Security) }
$$

- Improving food security policies to improve food patterns and cultural patterns

- Teaching the correct use of natural resources and adapting to climate change

- Teaching the proper use of water resources and new methods of irrigation

- Improving the diagnosis of quality product

- Increasing the knowledge and information of skilled workers in using the product Safety (Food Security)

- Improving the quality of rice grains through training new cultivation practices

- Using mechanisms to ensure the health of the food 
- Accessing healthy and nutritious food

Accessibility (Food Security)

- Improving access to credit and savings systems

- Improving access to input and outlet markets

- Strengthening access to knowledge and information

0.656

- Empowering women and improving their access to resources

0.652

- Improving access to natural resources (land, water)

0.651

- Increasing revenue for microprocessors

0.655

- Improving the supply of food for the vulnerable majority

$$
\text { Availability (Food Security) }
$$

- Improving and restoring resources, especially land

- Investing in new and consistent technologies

0.656

- Investing in rural markets

0.654

- Investing in infrastructure in villages

- Improving consumption patterns through a variety of training programs

0.651

- Improving research and innovation in agriculture

0.648

- Possibly improving food production in the countryside, especially through small-scale farmers

$$
\text { Social-Cultural Requirements }
$$

- Ensuring the effectiveness of institutions in improving local innovation capacity through the creation of craft exhibitions, food industry, holding rice festivals, etc.

- Empowering small-scale producers to participate in the policymaking and decision-making process

- Reducing poverty reduction through self-sufficiency in rice production

- Improving gender equality through empowerment of rural women

- Promoting institutional networking and interaction between institutions (collaboration among cooperatives, etc.) in sharing information

- Strengthening social capital (trust, honesty, goodwill, self-healing, hedonism, friendship, solidarity, sacrifice, etc.)

- Building capacity and empowerment of local people

0.803

- Improving nutritional patterns and food preferences through culture

- Increasing flexibility in vulnerable populations through increased awareness

- Improving nutritional quality and food security

- Improving access (physical and financial) to imported markets (seeds, fertilizers, poisons, etc.)

- Improving access (physical and financial) to outbound markets (product)

- Determining guaranteed purchase price

0.797

- Strengthening access for financial assistance to financial services (insurance, etc.)

- Improving collective investment by fundraisers and community members

- Creating sustainable livelihoods through the development of tourism and home care

- Reducing the cost of merchant transactions (such as shipping costs, marketing, etc.) 
- Increasing reliance on non-agricultural economies (agriculture)

- Ensuring the effectiveness of rural institutions in improving government finance and credit, such as loans, subsidies, etc.

- Creating job opportunities for farmers

According to the results presented in Table 6, we conclude the following:

Among the observed variables, the greatest impact is related to the following variables in order of importance:

- "Strengthening access to knowledge and information" is related to educational requirements with a path coefficient of 0.814 .

- "Using new technologies in agriculture, such as nanotechnology, nuclear technology, etc." is related to technical requirements with a path coefficient of 0.812 .

- "Strengthening the access of rice growers to water resources and optimizing their management" is related to infrastructure requirements with a coefficient of 0.812 .

- 'Ensuring that small farmers' voices are heard by the authorities to participate in the policy and decision-making process" is related to policy requirements with a path coefficient of 0.812 .

- "Ensuring effectiveness of institutions in improving local innovation capacity through the creation of handicraft exhibitions, food industry, holding rice festivals, etc." is related to socio-cultural needs with a path coefficient of 0.812 .

- Improving access (physical and financial) to imported markets (seeds, fertilizers, pesticides, etc.) and "improving access (physical and financial) to outsourced markets (product)" related to economic requirements with a path coefficient of 0.812 .

Moreover, all of these variables were the most important variables according to the research background and experts' opinions.

\section{Discussion}

Ciheam (2013) asserted that by providing a consistent set of services, rural innovative manufacturing organizations can increase farmers' incomes and improve food security. These services include improving access to and management of natural resources, information and technology and facilitating participation in policymaking processes.

- In the present research, economic requirements have a positive impact on improving food security, which include the following:

- Improving the financial and physical access of farmers to input markets (seed, fertilizer, poison, etc.) and improving the financial and physical access of outsiders to outsourced markets (the product), which are consistent with the findings of the studies by CIHEAM (2013), Mumuni and Oladele (2016), 
IFAD (2008), Silvestri et al. (2015), Olayemi and McIntyre (2014) and Herbel et al. (2012).

- Strengthening access of rice growers to financial services (insurance, etc.), which is in line with the findings of CIHEAM (2013), FAO (2016) and NRI (2016).

- Reducing transaction costs for traders (such as product cost, marketing, etc.), which is consistent with the findings of Biénabe and Sautier (2005).

- Improving collective investment of rice growers and members of the association and institution, which is in line with the findings of Mumuni and Oladele (2016) and Herbel et al. (2015).

- Increasing income and creating job opportunities for rice growers, which is in line with the findings of Keshavarz and Karami (2014), IFAD (2003) and Wabwoba and Wakhungu (2013).

- Improving government finance and credit, such as loans, input subsidies, etc., which is in line with the findings of CIHEAM (2013) and Keshavarz and Karami (2014).

- Creating sustainable livelihoods through the development of tourism and home care, which is consistent with the findings of Uphoff and Buck (2006).

- Determining the guaranteed purchase price, a variable that has been extracted from the results of interviews with experts in the Delphi qualitative section.

- The results showed that socio-cultural requirements have a positive effect on improving food security, which include the following:

- Empowering small-scale producers to participate in policymaking and decision-making processes, which is in line with the findings of Herbel et al. (2012), FAO (2016) and IFAD (2003).

- Reducing poverty through self-sufficiency in rice crops, which is consistent with the findings of Bishwajit et al. (2013).

- Strengthening social capital (trust, honesty, good luck, self-esteem, hedonism, friendship, solidarity, sacrifice, etc.), which is consistent with the findings of Nejatian et al. (2014).

- Building capacity and localization of locals, which is in line with the findings of Waters-bayer et al. (2015) and IFAD (2003).

- Promoting institutional networking and inter-institutional interaction (collaboration between institutions) in sharing information, which is consistent with the findings of Agrawal and Perrin (2009) and NRI (2016).

- Improving nutritional patterns and food preferences through culture, which is consistent with the findings of Saadi et al. (2014) and Guyomard et al. (2012).

- Improving the quality of nutrition and food security, which is consistent with the findings of Mcinerney (2014), European Commission (2015), Watersbayer et al. (2015) and Balie (2009).

- Ensuring the effectiveness of institutions in enhancing local innovation capacity through the creation of handicraft exhibitions, food industry, rice festivals, etc., which is consistent with the findings of Waters-bayer et al. (2015). 
- Increasing flexibility in vulnerable populations by raising awareness, which is consistent with the findings of CIHEAM (2013), Mumuni and Olade (2016), NRI (2016), European Commission (2015) and Waters-bayer et al. (2015).

- Improving gender equality through empowerment of rural women, which is consistent with the findings of Movahedi and Samian (2014) and Mcinerney (2014).

- In this study, infrastructure requirements had a positive effect on improving food security, which include the following:

- Strengthening access to water resources and optimal management, which is consistent with the findings of John and Fielding (2014), Mcinerney (2014), CIHEAM (2013), Herbel et al. (2012) and FAO (2016).

- Improving the access of rice growers to cultivated land suitable for cultivation, which is consistent with the findings of Keshavarz and Karami (2014) and Wabwoba and Wakhungu (2013).

- Improving the access of rice growers to appropriate equipment for the preparation and modernization of agricultural land, improving the access of rice growers to the appropriate transportation system, improving access of rice growers to ICT, and creating conversion and supplementary factories in villages, all of which were extracted through interviews with experts and using the Delphi qualitative method.

- Moreover, according to the results, policy requirements for improving food security have a positive effect on food security. These requirements are as follows:

- Ensuring that the voice of small-scale producers heard by the authorities to participate in the policymaking and decision-making processes, which is consistent with the findings of Herbel et al. (2012), FAO (2016) and IFAD (2003).

- Promoting local governance and decentralization in rural management programs, which is consistent with the findings of Moradi and Papzan (2014), NRI (2016), Agrawal and Perrin (2009) and Briner and Wittmer (2000).

- Establishing appropriate rules to reduce conflicts over land, which is consistent with the results of NRI (2016).

- Establishing a targeted, coordinated and coherent planning system in villages, which is in line with the findings of Wabwoba and Wakhungu (2013) and the European Commission (2015).

- Improving product pricing policies, which is consistent with the results of Keshavarz and Karami (2014) and Balié (2009).

- Improving the policy of subsidizing loans to farmers, improving support policies for energy saving and energy, improving the policies for the import and export of rice products, and integrating land slabs, all of which are extracted from the results of interviews with experts using the qualitative Delphi method.

- The results of the research show that educational requirements have a positive effect on the improvement of food security, which include the following: 
- Strengthening access to knowledge and information, which is in line with the findings of Mumuni and Oladele (2016), John and Fielding (2014), Silvestri et al. (2015) and Herbel et al. (2012).

- Holding a variety of local classes, such as developmental classes, etc., which is in line with the findings of McInerney (2014), CIHEAM (2013), Herbel et al. (2012) and Saadi et al. (2014).

- Increasing human capital through specialist training, which is in line with the findings of Keshavarz and Karami (2014).

- Using the FFS method and organizing a rice farm day, holding workshops on rice crop operations, organizing publications and journals on rice crops, and enhancing the proper use of indigenous and local knowledge, which are derived from expert interviews using the Delphi qualitative approach.

- Finally, based on the results of the research, technical requirements affect the improvement of food security, including the following:

- Using modern technologies in agriculture such as nanotechnology; using appropriate technology in planting, preserving and harvesting; using modern methods in irrigation; using hybrid seeds and modified varieties; using machines for transplanting; and multipurpose use of rice cultivation such as rice cultivation with duck breeding, fish, etc., all of which are in line with the findings of Herbel et al. (2015), John and Fielding (2014), Mbaga (2013), Keshavarz and Karami (2014) and Uphoff and Buck (2006).

\section{Conclusion}

Poverty and food insecurity are closely interrelated; poor food and nutrition have a major effect on human health, reduce human development and, in the long-run, reduce labor productivity. Food security is an integral part of international development policies. Creating a nationally effective system for ensuring food security, in addition to helping to improve nutrition and community health, will improve food industry and increase production and income levels. Thus, improving the infrastructure and existing policies is important in creating a nationally effective food control system (Pereira et al., 2014).

Innovative institutions, as living structures and organizational dynamics, have a positive effect on creativity and innovation as these structures are less formalized and focused. With their greater flexibility, these institutions can adapt to the needs of the environment to facilitate creativity and innovation. The environment is constantly evolving; therefore, organizations, including cooperatives, must adapt to new conditions to survive and even to maintain the status quo. Such adaptations require factors such as innovation and creativity in the organization. In fact, innovation is a response by organizations to the transformation of the market to compete with other companies to ensure their survival and growth and to improve management considering the innovations of the day. Certain principles and frameworks applied by companies in a competitive environment are applicable for transforming organizations in terms of structure, workflow, the identification of the main and secondary processes, organizational culture, etc. Improving the adaptability of organizations has attracted the attention of many experts, and adaptability can make organizations more effective and efficient in the turbulent and uncertain world of today (Moosavi et al., 2014). One of the main functions of innovative rural organizations is to improve food security. The 
definition of household food security is the physical, social and economic access of members of the family to healthy, complete and sufficient diets all the time that satisfy dietary requirements and their willingness to eat to have a healthy life. Access to healthy and nutritious foods, receiving adequate food and being free from hunger are essential. In addition to having food available to the household, there must be the financial ability to buy food to have "food security."

Findings of this research show that the Technical Requirements have the most impact on Food Security so the rural innovative institutions can train and educate the new technologies to the small- scale farmers such as Nano technologies and Nuclear technologies. For example, Silver Nano particles that could raise the efficiency of rice fields and production of rice varieties that resistant to the drought and salinity through nuclear technology.

Also, one of the important and innovative matters in these results that should considered is the impact of all the requirements on accessibility in food security, because of geographic condition and lack of water resources the rural innovative institutions could work on some practical ways for these problems, include the improving access to the small dams and reduce the water consumption with the new methods such as System of Rice Intensification (SRI) and Rice Dry-Soil.

At the end, the following suggestions are made to improve food security through the creation of rural innovative institutions:

- Acquiring indispensable materials at the local level: For the development of agriculture in developing countries, access to five essential resources is essential: capital (land, machinery, and renewable resources such as water), markets (for example, infrastructure adequacy, communication networks that provide farmers with access to the latest prices and the ability to meet the supply standards in supermarkets), credit (preventing early product sales by small farmers or improving access to basic facilities such as fertilizers), knowledge (in cases where there is an urgent need to invest in agricultural subsidiary services to help research be transformed to the work environment) and risk management tools.

- Improving access to social support: Support networks in the country can be created by rural cooperatives in different rural areas, making food products locally much cheaper to the people of the same area. Agricultural policies, which generally take into account macroeconomic interests, should pay attention to the food security of people in deprived areas at a micro level, as the development of these areas will play a major role in the development of the country in the future. The most important point is preventing the compound burden of malnutrition, hunger and poverty, and all the social disadvantages of poverty, which will extend into other areas of the country. Providing food security in remote rural areas is only possible through social and agricultural support.

- Improving access to land and other assets by implementing programs based on social risk management and the empowerment of poor rural households. The strengthening of social capital and the use of collective action and sharing scarce resources can help improve the livelihoods of small-scale farmers and poor households.

- Promoting the culture of nutrition in rural areas by conducting educational courses and developing radio and television programs. 
- Holding vocational relearning courses to increase the level of education of the head of household to increase human capital.

- Policy-makers and development practitioners need to improve their understanding of institutional change.

- Innovative partnerships between small producers, governments and the private sector must be considered and built.

Recommendation for future studies:

- In this research, innovative organization was studied for rice growers we recommend that other researcher study on wheat grower.

- The requirements of establishing rural innovative institution in this research were surveyed in six variables as independent (observe) variables and the dependent variable is food security. So, we recommend that other researchers work on other factors such as environmental requirements.

\section{REFERENCES}

[1] ADB (Asian Development Bank) (2013): Food Security in Asia and the Pacific. - Liu Institute for Global Issues, Mandaluyong City, Philippines.

[2] Agrawal, A, Perrin, N. (2009): Mobilizing Rural Institutions: A Comparative Study of Rural Institutions for Improving Governance and Development: Afghanistan, Ethiopia, India, Vietnam, and Yemen. - Social Development Papers, Community Driven Development \& Local Governance 114, April 2009.

[3] Allameh, A. A. (2012): Food Security, Sustainable Agriculture, Health. - Agricultural Jihad Organization, Khorasan Razavi.

[4] Bakhsi, M, Samadi, M, Nasiri, M. (2008): Alignment of Iran's position in the Southwest Asia region based on indicators of vulnerability and food security. - Agricultural Economy and Development,16(63): 21-50, Retrieved from: http://www.sid.ir/fa/journal/ViewPaper.aspx?ID=93660

[5] Balié, J. (2009): Enhancing Food Security and Nutrition Policy Assistance: Lessons from Experience. - Policy Assistance Series 5. Food and Agriculture Organization of the United Nation with the Support of the FAO Netherlands Partnership Programme, Rome.

[6] Bishwajit, G. H., Sarker, S, Kpoghomou, M. A, Gao, H, Jun, L, Yin, D., Ghosh, S. H. (2013): Self-sufficiency in rice and food security: a south Asian perspective. Agriculture and Food Security 10(2).

[7] Briner, R., Wittmer, H. (2000): Converting Social Capital into Political Capital. How Do Local Communities Gain Political Influence? A Theoretical Approach and Empirical Evidence from Thailand and Columbia. - Paper submitted to the 8th Biennial Conference of the International Association for the Study of Common Property, Indiana, 2000.

[8] CIHEAM (2013): Rural Development in the Mediterranean Countries. - Watch Letter No. 24, March 2013.

[9] Cronbach, L. J. (1951): Coefficient alpha and the internal structure of tests. Psychometrika 16(3): 297-334.

[10] European Commission (2015): Global food security: challenges and options. - EU Agricultural Markets Briefs No. 9, November, 2015.

[11] FAO (2016): FAO's Role in Strengthening Rural Institutions and Organizations. - Rural Institutions, FAO, Rome.

[12] FAO, IFAD, WFP (2014): The State of Food Insecurity in the World 2014. Strengthening the Enabling Environment for Food Security and Nutrition. - FAO, Rome. 
[13] Guyomard, H., Darcy-Vrillon,, B., Esnouf, C., Marin, M., Russel, M., Guillou, M. (2012): Eating patterns and food systems: critical knowledge requirements for policy design and implementation. - Agriculture \& Food Security 13(1).

[14] Hamidifar, R. (2012): A Solution Called Resistance Economics. - Tebyan Society and Policy Group, Retrieved from: https://article.tebyan.net/131429

[15] Herbel, D., Crowley, E., Ourabah Haddad, N., Lee, M. (2012): Good Practices in Building Innovative Rural Institutions to Increase Food Security. - FAO, Rome.

[16] Herbel, D., Rocchigiani, M., Ferrier, C. H. (2015): The role of the social and organizational capital in agricultural cooperatives' development practical lessons from the CUMA movement. - Journal of Co-operative Organization and Management 3: 24-31.

[17] IFAD (2008): Institutional and Organizational Analysis for Pro-poor Change: Meeting IFAD's Millennium Challenge. Enabling Poor Rural People to Overcome Poverty. A Source Book. - IFAD, Rome.

[18] John, A., Fielding, M. (2014): Rice production constraints and 'new' challenges for South Asian smallholders: insights into de facto research priorities. - Agriculture \& Food Security 18(3).

[19] Keshavarz, M., Karami, A. (2014): Analysis of food insecurity in rural communities in Iran using Tyasn statistical theory: strategies to promote. - Congress of Agricultural Extension and Education Sciences and Natural Resources Iran, Association of Agricultural Extension and Education, Iran.

[20] Lee, S. Y. (2007): Structural Equation Modeling: A Bayesian Approach. - John Wiley \& Sons.

[21] Mbaga, M. D. (2013): Alternative mechanisms for achieving food security in Oman. Agriculture \& Food Security 3(2).

[22] McInerney, E. (2014): Cooperative Key to Achieving Sustainable Agricultural Development. - FAO, Rome.

[23] Olayemi, M., McIntyre, L. (2014): Determinants of food insecurity in higher-income households in Canada. - Journal of Hunger \& Environmental Nutrition 9(4): 433-448.

[24] Moosavi, S., Farajollah-Hosseini, J., Mirdamadi, M. (2014): Social factors effecting on improving innovation management in agricultural and rural cooperatives of Tehran Province. - Journal of Cooperative and Agriculture 3(9): 19-40. Retrieved from: http://ajcoop.mcls.gov.ir/article_8786.html

[25] Moradi, K. H., Popzan, A. (2014): Rural Management in the Light of Local Governance. - Congress of Agricultural Extension and Education Sciences and Natural Resources Iran, Association of Agricultural Extension and Education, Iran.

[26] Movahedi, R., Samian, M. (2014): Improving and strengthening rural women's organizations. - Congress of Agricultural Extension and Education Sciences and Natural Resources Iran, Association of Agricultural Extension and Education, Iran.

[27] Mumuni, E., Oladele, O. I. (2016): Access to livelihood capitals and propensity for entrepreneurship among rice farmers in Ghana. - Agriculture and Food Security 5(1). https://doi.org/10.1186/s40066-015-0049-x.

[28] Natural Resources Institute (2016): Land, Rural Institutions and Governance. University of Greenwich, Greenwich.

[29] Nejatian, S. H., Yaghoobi, J., Popzan, A. (2014): Factor analysis hinder the creation and maintenance of social capital in agricultural cooperatives (case study agricultural cooperatives city of Zanjan). - Congress of Agricultural Extension and Education Sciences and Natural Resources Iran, Association of Agricultural Extension and Education, Iran.

[30] Pereira, L. M, Cuneo, C. N, Twine, W. C. (2014): Food and cash: understanding the role of the retail sector in rural food security in South Africa. - Journal of Food Security 6: $339-357$. 
[31] Rostami, F; Shahmorady, M, Baghae, S. (2014): Factors affecting food security of rural households (Case Study: Karnachi village, the city of Kermanshah). - Iranian Journal of Agricultural Economics and Development 45(4): 725-737.

[32] Saadi, H., Azizi, M., Azami, M. (2014): Extension education and food security, farmer households (Case Study: City Qorveh). - Iran Agricultural Economics and Development Research 45(3): 499-483.

[33] Sen, A. K. (1981): Poverty and Famines: An Essay on Entitlement and Deprivation. Clarendon Press, Oxford.

[34] Silvestri, S., Douxchamps, S., Kristjanson, P., Förch, W., Radeny, M., Mutie, I., Quiros, C. F., Herrero, M., Ndungu, A., Nicolas, N., Mango, J., Claessens, L., Rufino, M. C. (2015): Households and food security: lessons from food secure households in East Africa. - Agriculture and Food Security 23(4). https://doi.org/10.1186/s40066-015-00424.

[35] Uphoff, N., Buck, L. (2006): Strengthening rural local institutional capacities for sustainable livelihoods and equitable development. - Paper prepared for the Social Development Department of the World Bank. World Bank, Washington, DC.

[36] Wabwoba, M. S., Wakhungu, J. W.(2013): Factors affecting sustainability of community food security projects in Kiambu County, Kenya. - Agriculture and Food Security 9(2).

[37] Waters-bayer, A., Kristjanson, P., Wettasinha, C. H., Van Veldhuizen, L., Quiroga, G, Swaans, K., Douthwaite, B. (2015): Exploring the impact of farmer-led research supported by civil society organisations. - Agriculture and Food Security 4(4).

[38] World Agroforestry Centre (ICRAF) (2014): Strengthening Rural Institutions Project (Jan 2011 to Dec 2014). - ICRAF, Nairobi. 